Check for updates

Cite this: RSC Adv., 2019, 9, 781

Received 12th October 2018

Accepted 20th December 2018

DOI: $10.1039 / \mathrm{c} 8 \mathrm{ra0} 8453 \mathrm{j}$

rsc.li/rsc-advances

\title{
Fe/Zn-modified tricalcium phosphate (TCP) biomaterials: preparation and biological properties $\dagger$
}

\author{
Lu Xie, ${ }^{a}$ Yuanyi Yang, ${ }^{\mathrm{b}}$ Zhiqiang Fu, ${ }^{\mathrm{c}}$ Yunfei Li, ${ }^{\mathrm{d}}$ Jiacheng Shi, ${ }^{\mathrm{d}}$ Daichuan Ma, \\ Suilin Liu ${ }^{e}$ and Daibing Luo iD *e
}

Bone repairing materials play an essential role in the repair treatment of bone defects. The presence of calcium phosphate invertebrates is of significance for bone repairing processes. However, the mechanical properties and osteogenic activities of many current calcium phosphate materials are not ideal, which limit their biological applications. Therefore, it is an effective alternative strategy to study the modification of calcium phosphate biomaterials to address these limitations. In this research, in order to enhance the biological performance of tricalcium phosphate ( $\beta$-TCP), metal species (Fe and $\mathrm{Zn}$ ) modified $\beta$-TCP materials through the co-precipitation method were successfully developed. The physical, chemical and biological properties of the binary composites were carefully studied for the first time. The bioactivities of the Fe-TCP and Zn-TCP were evaluated by simulating body fluid (SBF) immersion experiments, blood compatibility, and cytotoxicity tests. The findings demonstrated that the metal-TCP with excellent cytocompatibility and osteogenic properties shows good potential in medical applications.

\section{Introduction}

Biomedical materials, especially high quality bone repair materials, are in growing demand year by year because the incidence of bone deficiencies typically leads to unexpected osteoporosis, trauma, congenital malformations, and surgical resections. ${ }^{1}$ However, currently $90-95 \%$ of substitutional materials for bone tissues are obtained from the patients themselves and other donors. Moreover, the popular bonerepair processes bring pains to the patients and donors and increases the possibility of infection and other complications..$^{2,3}$ Moreover, implant failure and even bone resorption may occur due to mismatched elasticity between the implant metals and adjacent bone tissues. To overcome these limitations, artificially synthesized bone-repair materials can be used to effectively decrease the damage caused by the second surgery and

${ }^{a}$ State Key Laboratory of Oral Diseases, National Clinical Research Center for Oral Diseases, Department of Prosthodontic, West China Hospital of Stomatology, Sichuan University, Chengdu, 610041, China

${ }^{b}$ Department of Materials Engineering, Sichuan College of Architectural Technology, Deyang, 618000, China

${ }^{c}$ School of Chemical Engineering, Sichuan University, Chengdu, 610065, China

${ }^{d}$ School of Materials Science and Engineering, Sichuan University, Chengdu, 610064, China

${ }^{e}$ Analytical \& Testing Center, Sichuan University, Chengdu 610064, China. E-mail: luodb@scu.edu.cn

$\dagger$ Electronic supplementary information (ESI) available. See DOI: 10.1039/c8ra08453j significantly reduce the possibility of infection and complication. Furthermore, the use of synthesized bone-repair materials is low cost, hence the research on the bone-repair materials is of great significance in medicine in view of economy. Biomaterials based on tricalcium phosphate $\left(\mathrm{Ca}_{3}\left(\mathrm{PO}_{4}\right)_{2}, \mathrm{TCP}\right)$ have similarity with inorganic components and the bioactivity of human bone tissue, so TCP biomaterials are widely used in both bone tissue engineering and clinical medicine. Now their medical research and application are one of the focuses among the universal researchers.

TCP is one of the most important $\mathrm{Ca} / \mathrm{P}$-containing compounds. TCP has a density of $3.14 \mathrm{~g} \mathrm{~cm}^{-3}$ and a Ca-P mole ratio of 1.5 , which is similar to that of $\mathrm{Ca}-\mathrm{P}$ components in human bodies. In addition, TCP has excellent biocompatibility and osteoconductive properties. ${ }^{4}$ Furthermore, TCP can be easily degraded to supply $\mathrm{Ca}$ and $\mathrm{P}$ elements for the requirement of human bone tissues to induce the growth of new bones. TCP has typically two kinds of crystalline phases: one is known as $\alpha$-TCP (monoclinic) with high-temperature stability, which can be obtained from the TCP precursor by calcination treatment at above $1250^{\circ} \mathrm{C}$. Another one is $\beta$-TCP (hexagonal) phase with low-temperature stability, which is generated from the TCP precursor by calcination treatment at around $1000{ }^{\circ} \mathrm{C}$. As one crucial biomaterial used in biodegradation ceramics, $\beta$-TCP is more widely studied than $\alpha$-TCP. Even pure $\beta$-TCP does not exist in hard tissues of human organisms, it is often used as a repair material for artificial bones due to its excellent degradable property and biocompatibility. Now there are many methods for 
$\beta$-TCP preparation, such as precipitation, ${ }^{5}$ sol-gel technique, ${ }^{6}$ hydrothermal synthesis, ${ }^{7}$ solid state reaction, ${ }^{8}$ mechanochemical reaction, ${ }^{9}$ and acid-base neutralization methods. ${ }^{10}$ However, according to some recent reports, $\beta$-TCP shows a limitation in stimulation of the generation of bones or restrain of the absorption of bones. Until now it is still a challenge to synthesize TCP materials with high degradable ability. Hence the research on the modification of $\beta$-TCP materials has vital sense to improve their biological properties. As an effective alternative, $\beta$-TCP materials are generally modified with macromolecules or doped ions. ${ }^{11-14}$

Metals are considered as ideal dopants for the modification of $\beta$-TCP materials. $\beta$-TCP materials can be doped with many kinds of metal elements. Doping the necessary trace elements into $\beta$-TCP may afford it extra functionality or improve the mechanical properties. In the degradation process of the metaldoped composites, some elements for the growth of bone tissues such as $\mathrm{Ca}$ and $\mathrm{P}$, and several kinds of metal nutrient elements, are released to improve the efficiency of bone repair processes. Fe as an essential element for human necessary can be combined with hemoglobin and participate in the transportation and storage of oxygen, which greatly promotes the bone growing development and the resistance to disease. On the other hand, the iron (Fe) deficiency will cause hypoferric anemia. Fe element, with a high content in human bodies, mainly exists as $\mathrm{Fe}^{2+}$ or $\mathrm{Fe}^{3+}$ ions in connection with hemoglobin and myohemoglobin. $\mathrm{Fe}^{3+}$ ions have excellent bioactivity in relationship to many kinds of the enzymes. They participate in the hematopoiesis, oxygen transportation, synthesis for the enzyme of protein and cytochrome. Zn element, as another important one of the trace elements for human body necessity, plays an essential role in the protein construction, assistance of metabolism, and the synthesis of specific enzymes. Additionally, it has a significant impact on the maintaining the bone metabolism since it can restrain the osteogenesis of osteoclast and boost the osteogenesis of osteoblast. It is well known that acalcerosis due to $\mathrm{Zn}$ deficiency causes much orthopedics diseases, but high-concentration of $\mathrm{Zn}$ in human bodies brings serious side-effect.

Even progress has been made toward the development in metal modified TCP, concerns are rising on the potential release of harmful species of metal composites in vivo. ${ }^{15}$ The degradation rate range of some metal-doped $\beta$-TCP may still not adequately satisfy clinical requirements. The mismatched elasticity between the metals and bone tissues is another widespread problem that results in implant failure and bone resorption. Until now the research on Fe-doped TCP is not much while $\mathrm{Fe}$ in the elementary form introduced into $\beta$-TCP has been studied as a typical example. ${ }^{16}$ The toxicity of the composite biomaterials doped with elementary Fe is still worthy of investigation in depth. Zn-TCP materials with better bioactivity can enhance the cell differentiation and the expression of alkaline phosphatase. ${ }^{17}$ On the other hand, Zn-doped TCP materials are now widely studied, but side effects of cytotoxicity caused by the release of $\mathrm{Zn}^{2+}$ at a higher rate if a high amount of $\mathrm{Zn}$ is doped into $\beta$-TCP materials, should be seriously considered. To our best knowledge, works involving in vitro degradation and bioactivity for Fe/Zn-TCP biomaterials in simulating body fluid (SBF) are not deeply investigated and reported. In this article, we studied the enhanced effect for the bone repair by doping Fe and Zn elements into $\beta$-TCP materials. The biological property after the modification was evaluated in detail. The effects of these metal ions in the crystalline structures and the thermal stability were also investigated.

\section{Experimental}

\subsection{Reagents and instrumental}

All the inorganic reagents, with AR purity or higher grade, were purchased from Chengdu Kelong Chemical Reagent Company. The CCK-8 solution was obtained from Shanghai Biyuntian Biotechnology Co. Ltd. The PBS (phosphate buffer saline) and SBF (simulated body fluid) solutions were prepared according to the standard manual in the laboratory. The DMEM (Dulbecco's modified Eagle medium) incomplete high sugar medium (KGM12800-500) was provided by Jiangsu Kaiji Biotechnology Co. Ltd. De-ionized water (D.I. water) was used to prepare all aqueous solutions.

The crystalline phase of the samples was examined by X-ray diffraction analysis (XRD, Philips X'Pert, Netherlands) using a Cu target working at $40 \mathrm{kV}(\lambda=1.540598 \AA)$. The diffraction angles $(2 \theta)$ were measured between $10^{\circ}$ and $70^{\circ}$. Comparison of the sample diffraction pattern with standard cards in ICCDJCPDS database was performed to identify the sample phase.

The surface morphologies of the samples were observed by field scanning electron microscopy (FE-SEM, S450, Hitachi, Japan). The samples were sputtered with gold films before placed into the device. The SEM was operated at an accelerating voltage at $5 \mathrm{kV}$.

The differential scanning calorimeter (TG-DSC) was carried out to find the phase transformation and to identify the products using STA449C (NETZSCH, Germany). The species used for the test was cut about $10 \mathrm{mg}$ from the bulk. The samples were heated from $20{ }^{\circ} \mathrm{C}$ to $900{ }^{\circ} \mathrm{C}$ with a heating rate of $10{ }^{\circ} \mathrm{C} \mathrm{min}{ }^{-1}$ under nitrogen protection.

The mechanical experiment was carried out by a single-grain compressive strength tester (TS-14, Chengdu, China) at a loading velocity of $3 \mathrm{~cm} \mathrm{~min}^{-1}$. The ultimate tensile strength and bending strength of the composites were examined. The samples were cut to a standard cuboid with a $1 \mathrm{~cm}$ diameter and $0.5 \mathrm{~cm}$ thickness for the mechanical test with a loading rate of $441 \mathrm{~N} \mathrm{~min}^{-1}$.

\subsection{Preparation process}

The metal doped $\beta$-TCP precursors with different mole ratio (2, 5 , and $10 \%$ ) were prepared in the light of the $\mathrm{P}$ amount in mole criterion. $\left(\mathrm{NH}_{4}\right)_{2} \mathrm{HPO}_{4}$ solution was added into the metalcontaining $\mathrm{HNO}_{3}$ solution. Then the mixed solution was adjusted by ammonia to $\mathrm{pH}$ 9-10 by fast stirring for $1 \mathrm{~h}$. After that, the product was filtrated and washed with D.I. water for 3 times, followed by placing in the oven at $100{ }^{\circ} \mathrm{C}$ for $24 \mathrm{~h}$ to remove the absorbed water. 
Octadecanoic acid $\left(\mathrm{C}_{18} \mathrm{H}_{36} \mathrm{O}_{2}\right)(20 \%$ mass ratio), serving as the pore-forming agent, was added into the as-prepared precursor to generate the porous biomaterials. After the full mixing process, the sample was softly ground. PVA (polyvinyl alcohol, $3 \%$ mass ratio), serving as the binder agent, was then introduced into the mixture. The obtained sample was put into a pattern container and mould-shaped at a pressure of $10 \mathrm{MPa}$ for $3 \mathrm{~min}$. The agglomeration of the solid material with a slice shape was preceded in a muffle furnace. In this process, the temperature was slowly increased to $200{ }^{\circ} \mathrm{C}$ and kept for $1 \mathrm{~h}$, then was increased to $1000{ }^{\circ} \mathrm{C}$ and kept for $2 \mathrm{~h}$. After that, the samples were slowly cooled at ambient condition. The asprepared compact slice material was directly tablet compressed in the mould without porogen and adhesive agents. The tableting treatment was performed at $10 \mathrm{MPa}$ pressure for 3 min without moulding-shaping. Then the agglomeration of the sample was carried out in the muffle furnace at $1000{ }^{\circ} \mathrm{C}$ for $2 \mathrm{~h}$. The Fe/Zn-TCP preparation process is illustrated in Fig. 1 in detail.

The Fe-TCP and Zn-TCP products with different doping levels were characterized by XRD, IR, XPS, SEM, and TEM. The replacements of $\mathrm{Ca}^{2+}$ ions by $\mathrm{Fe}^{3+} / \mathrm{Zn}^{2+}$ ions in the TCP crystal lattice were discussed.

\subsection{In vitro experiment}

2.3.1. Metal ions releasing experiment. The Fe/Zn-TCP samples (5\% content) with micropores in slice shape after the agglomeration treatment were immersed in $30 \mathrm{~mL}$ of PBS solution. After soaking in a water-bath shaker at $37{ }^{\circ} \mathrm{C}$ for the scheduled period (7/14/21 days), the upper layer of clear solution was taken out, and $3 \mathrm{~mL}$ of $\mathrm{HCl}$ solution was added into it, followed by diluting to $10 \mathrm{~mL}$ in total. The metal ion concentration in the PBS solution was measured by Inductive Coupled Plasma (ICP) Emission Spectrometer device.

2.3.2. In vitro immersion experiment. The $\mathrm{SBF}$ was prepared by dissolving $\mathrm{NaCl}, \mathrm{NaHCO}_{3}, \mathrm{KCl}, \mathrm{K}_{2} \mathrm{HPO}_{4} \cdot 3 \mathrm{H}_{2} \mathrm{O}$, $\mathrm{MgCl}_{2} \cdot 6 \mathrm{H}_{2} \mathrm{O}, \mathrm{CaCl}_{2}$, and $\mathrm{Na}_{2} \mathrm{SO}_{4}$ in sequence in D.I. water. Then the solution was adjusted to $\mathrm{pH} 7.4$ with $\left(\mathrm{CH}_{2} \mathrm{OH}\right)_{3} \mathrm{CNH}_{2}$ (Tris) and $\mathrm{HCl}(1 \mathrm{M})$ at $37{ }^{\circ} \mathrm{C}$. The Fe/Zn-TCP (5\%) was sealed and immersed in $10 \mathrm{~mL}$ of SBF (1.5 times) solution, placing in the shaker bath for the ion releasing at constant $37^{\circ} \mathrm{C}$ kept by an incubator. The SBF solution was renewed every two days. After the immersion process for a certain period (7/14/21 days), the samples were taken out and dried to weight. Then after scheduled days of soaking in SBF, the possible generation of apatite on the sample surface was examined by SEM observation. Meanwhile, the concentrations of possible released metal species (Fe or $\mathrm{Zn}$ ) from the TCP biomaterials were measured. A pH meter (Sartorius, pb-10, Germany) was used to monitor the $\mathrm{pH}$ value of the solution. After the immersion treatment, the surface morphologies of the TCP samples were observed by SEM after covered with gold films.

2.3.3. Hemolysis test. The blood sample was obtained from Healthy New Zealand white rabbits (purchased from Third Military Medical University, Chongqing, China), which containing sodium citrate $(3.8 \mathrm{wt} \%)$ in $9: 1$ ratio was diluted with normal saline ( $4: 5$ volume ratio). The change of the species concentration was monitored by a UV-visible spectrophotometer (Shimadzu, UV-2401PC, Japan). We used the measurements of the light absorbance of the upper layer solution to detect the hemoglobin released from the red blood cells (RBC). The absorption value could be employed to estimate the hemolysis property of the metal-TCP samples after they contact the blood for a certain time. Calculation of the hemolytic ratio is referenced to eqn (1) as follows.

Hemolytic $\operatorname{ratio}(\%)=$

OD(experimental group) - OD(negative control group)

$$
\begin{aligned}
& \mathrm{OD} \text { (positive control group) - OD(negative control group }) \\
& \times 100 \%
\end{aligned}
$$

2.3.4. Cell toxicity evaluation. MG-63 cells were used to examine the cell proliferation on the Fe/Zn-TCP composites.

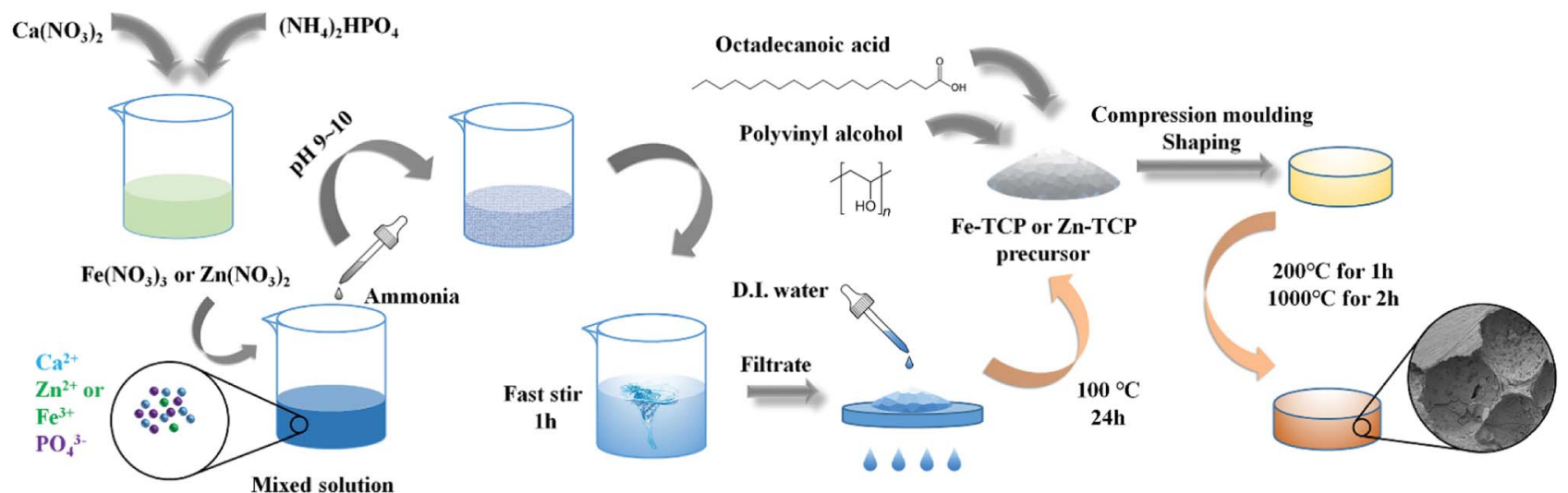

Fig. 1 Schematic elucidation the preparation of porous Fe-TCP and Zn-TCP. Through adjusting pH value and under stirring condition, the FeTCP and Zn-TCP precursors can be produced from the mixed solution. After washed, filtrated and dried, precursors were added by polyvinyl alcohol and octadecanoic acid. Finally, compression moulding shaping and agglomeration were carried to complete the production of porous Fe-TCP and Zn-TCP. 
The whole process included: (1) cell digestion; (2) cell count in $20 \mu \mathrm{L}$ of cell culture media by microscope observation (count unit: $\left.4 \times 10^{4}\right)$; (3) the diluted Fe/Zn-TCP samples were added into the holes each filled with $5 \times 10^{3}$ of MG-63 cells; (4) CCK-8 dyeing was used for 1,3 , and $5 \mathrm{~d}$, the absorption value of the upper layer solution in the culture media was measured at $450 \mathrm{~nm}$ with an ELISA (enzyme-linked immunosorbent assay) reader. Each group was two-fold parallel sampled. The RGR (relative growth rate) value was calculated according to eqn (2).

$$
\text { Relative added value }(\%)=
$$

$$
\frac{\text { absorption value of experimental group }}{\text { mean absoption value of negative control group }} \times 100 \%
$$

2.3.5. Statistics method. Six parallel samples in each group were chosen to calculate the average and standard deviation, which were employed to express the obtained data, and a confidential level of $95 \%(p<0.05)$ was regarded as the statistics difference.

\section{Results and discussion}

\subsection{Characterization}

3.1.1. XRD. XRD was used to compare the TCP precursors and the Fe/Zn-TCP samples after the agglomeration treatment. There are noticeable differences in the XRD patterns of $\beta$-TCP and the Fe/Zn-TCP products. The XRD patterns of the Fe-TCP precursors are shown in Fig. 2(a), and the XRD characterization for the Fe-TCP sample with different Fe content is indicated in Fig. 2(b). The main component of all the samples is hydroxyapatite. The XRD pattern of the Fe-TCP sample in main peaks is in accordance with that of the standard $\beta$-TCP (PDF\#090169). The diffraction intensity is increased when the $\mathrm{Fe}^{3+}$ content is less than $10 \%$. However, if the $\mathrm{Fe}^{3+}$ content is continuously increased than $10 \%$, the diffraction intensity is decreased, and the crystalline level becomes poor. The crystal cell parameters listed in Table S1 (ESI $\dagger$ ) of the Fe-TCP products are compared with the standard $\beta$-TCP sample, and they are in high similarity when the doping level of $\mathrm{Fe}^{2+}$ reaches to $2 \%$ content. If the $\mathrm{Fe}^{3+}$ concentration is higher than $5 \%$, the crystal cell parameter becomes smaller, indicating a shrinking of the cell and lower crystalline level. The distance between the
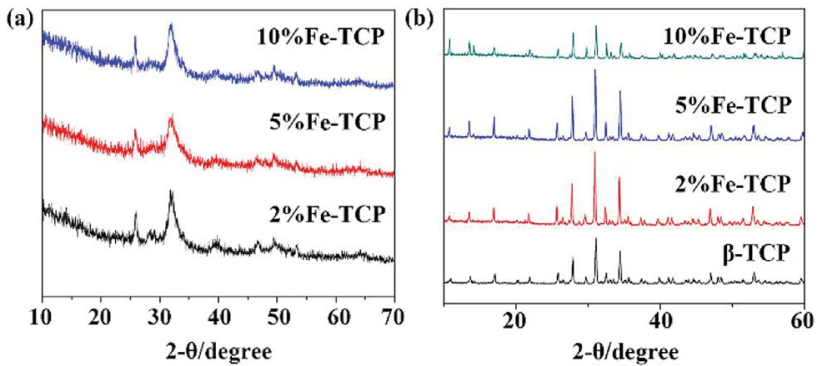

Fig. 2 XRD patterns of (a) the Fe-TCP precursors and (b) the Fe-TCP products.
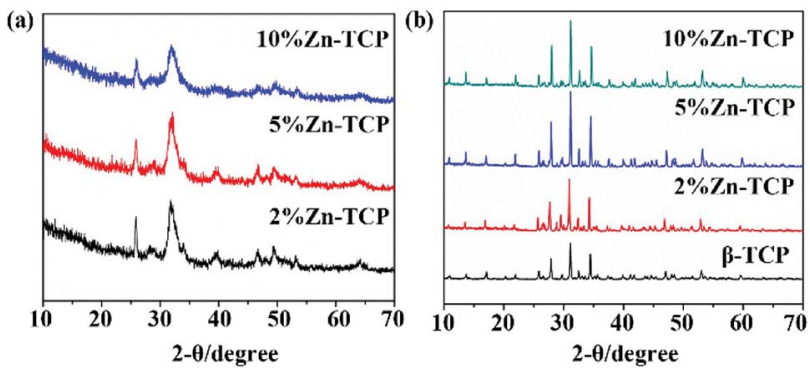

Fig. 3 XRD patterns of (a) the Zn-TCP precursors and (b) the $\mathrm{Zn}$-TCP products.

crystalline facets gets shorter because some $\mathrm{Ca}^{2+}$ ions are replaced by $\mathrm{Fe}^{3+}(0.064 \mathrm{~nm})$ ions that have a smaller ion diameter than that of $\mathrm{Ca}^{2+}(0.099 \mathrm{~nm})$ ions. If $10 \% \mathrm{Fe}^{3+}$ ions are introduced into the cell lattice, in order to balance the charge, some holes due to the loss of the $\mathrm{Ca}^{2+}$ ions are generated. In this case, cavities are produced that leads to the decrease of the cell lattice density. The presence of $\beta$-TCP is confirmed by the reflections at $27.8^{\circ}, 25.9^{\circ}, 31.2^{\circ}$, and $33.1^{\circ} .^{18}$

Similarly, analysis of the Zn-TCP XRD results is based on the curves in Fig. 3. The main component of them is also hydroxyapatite from the analysis of the diffraction peaks of the Zn-TCP precursors (Fig. 3(a)), which are similar to that of FeTCP precursors. The diffraction peaks are as same as that of the standard $\beta$-TCP samples (PDF\#09-0169). The peaks at $28.9^{\circ}$ and $29.5^{\circ}$ are caused by the presence of calcium pyrophosphate, indicating a small amount of calcium pyrophosphate was generated in the fabrication process. When the $\mathrm{Zn}$ doping level reaches to $5 \%$, the decreased cell parameters indicate a shrinking of the crystal cell. $\mathrm{Zn}^{2+}$ ions replace some $\mathrm{Ca}^{2+}$ ions in the cell along with the $\mathrm{Zn}^{2+}$ amount increasing. The distance between the crystalline facets becomes shorter because some $\mathrm{Ca}^{2+}$ ions are displaced by $\mathrm{Zn}^{2+}(0.074 \mathrm{~nm})$ ions that have a smaller ion diameter than that of $\mathrm{Ca}^{2+}(0.099 \mathrm{~nm})$. As a result, the crystal density gets larger and larger if more $\mathrm{Ca}^{2+}$ ions are doped in the cell lattice. Comparisons of the crystalline cell parameters and density between the Zn-TCP and $\beta$-TCP are indicated in Table S2 (ESI $\dagger$ ).

3.1.2. XPS. Differences between the $\beta$-TCP and Fe-TCP in XPS patterns are shown in Fig. 4. The peaks of $\mathrm{Ca}(2 \mathrm{p})$ of the $\beta$ TCP and Fe-TCP are almost the same by careful comparison. The characteristic peaks at 347.11 and $350.66 \mathrm{eV}$ are attributed to the $\beta$-TCP and hydroxyapatite (HA) respectively.$^{19}$ The energy spectral graph of the Fe (2p) of the Fe-TCP is indicated in Fig. 4(b). The 723.97 and $710.60 \mathrm{eV}$ peaks are ascribed to the Fe $2 \mathrm{p}_{1 / 2}$ and $\mathrm{Fe} 2 \mathrm{p}_{3 / 2}$ of the $\mathrm{Fe}-\mathrm{O}$ bond. ${ }^{20}$ The energy spectra of $\mathrm{O}$ (1s) are located at $532.35 \mathrm{eV}$ and $530.55 \mathrm{eV}$ (Fig. 4(c and d)) that are resulted from $\mathrm{OH}^{-}$and $\mathrm{PO}_{4}{ }^{3-}$ groups. ${ }^{21}$ The $529.54 \mathrm{eV}$ peak in Fig. 4(d) is the characteristic peak of $\mathrm{Fe}_{2} \mathrm{O}_{3}{ }^{22}$ The $\mathrm{P}(2 \mathrm{p})$ characteristic peaks, located at $132.86 \mathrm{eV}$ and $132.24 \mathrm{eV}$, are caused by $\mathrm{PO}_{4}{ }^{3-}$ groups as shown in Fig. 4 (e and f).${ }^{19}$ Based on the analysis, we concluded that the samples contain a small amount of HA. The $\mathrm{Fe}^{3+}$ ions in the Fe-TCP have two possible pathways in the synthesis reaction: (1) $\mathrm{Fe}^{3+}$ ions replace some $\mathrm{Ca}^{2+}$ ions in the $\beta$-TCP cell that causes the peak shift of $\mathrm{O}(1 \mathrm{~s})$ 

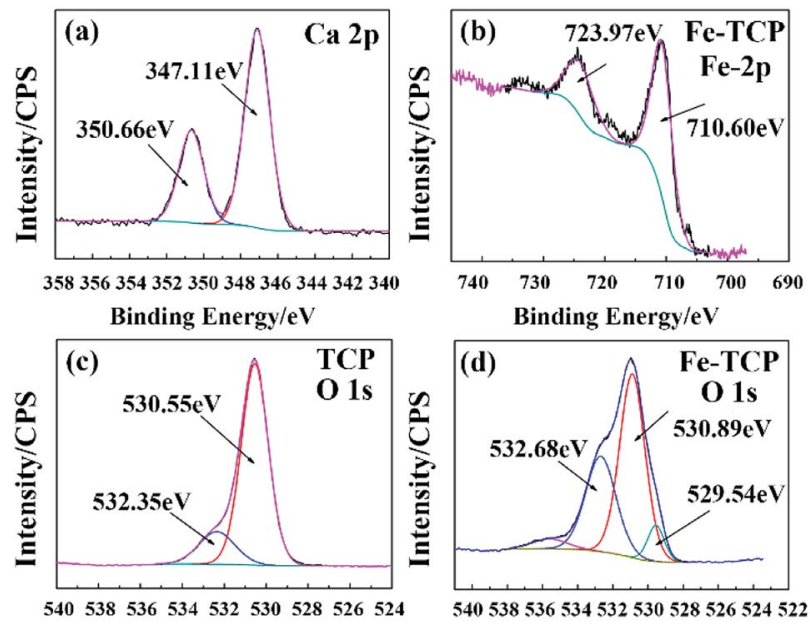

Binding Energy/eV

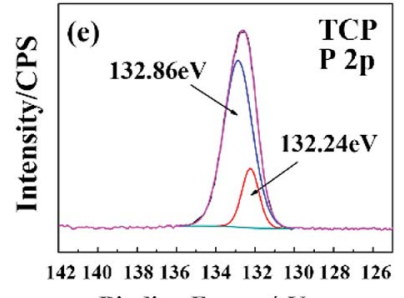

Binding Energy/eV

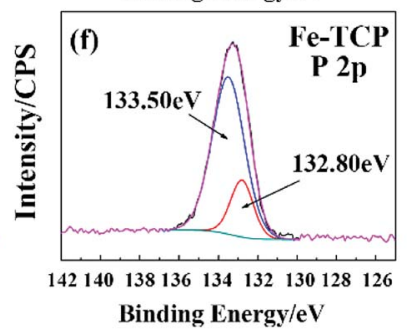

Fig. 4 XPS spectra of $\beta$-TCP (a, $c$ and e) and 5\% Fe-TCP (b, $d$ and $f$ ) with (a) Ca 2p, (b) Fe 2p, (c and d) O 1s, and (e and f) P 2p.
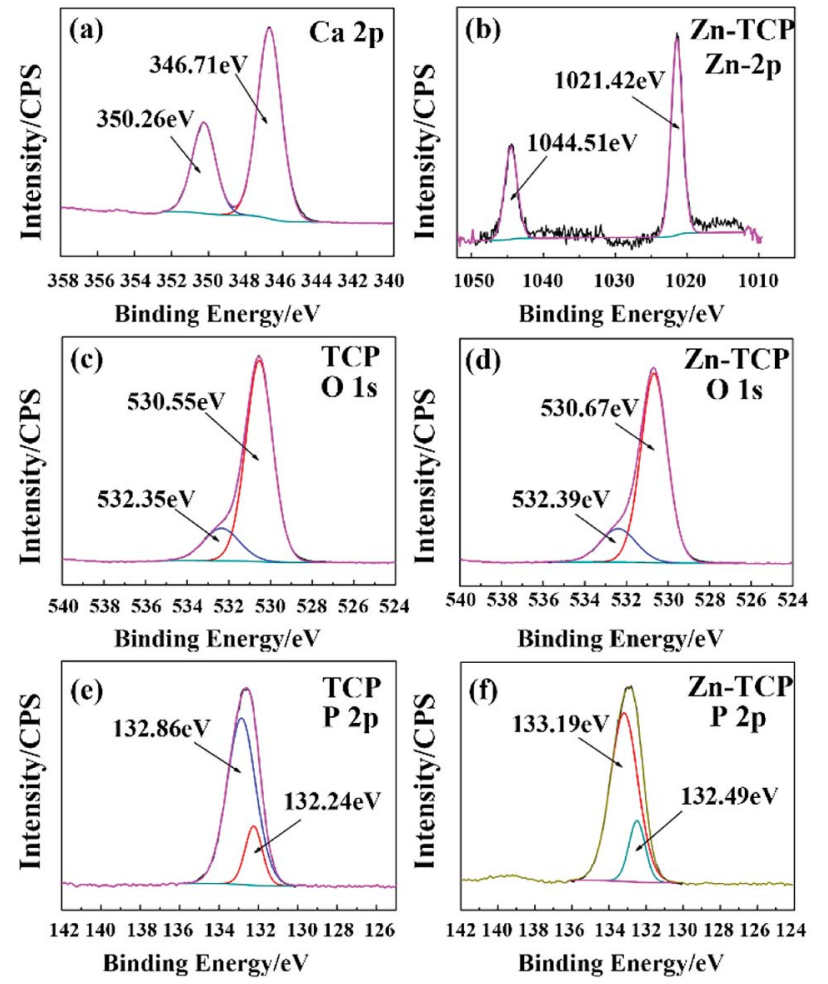

Fig. 5 XPS spectra of $\beta$-TCP (a, c and e) and $5 \% \mathrm{Zn}-\mathrm{TCP}(\mathrm{b}, \mathrm{d}$ and $\mathrm{f}$ ) with (a) Ca 2p, (b) Zn 2p, (c and d) O 1s, and (e and f) P 2p. and $\mathrm{P}\left(2 \mathrm{p}\right.$ ); (2) $\mathrm{Fe}^{3+}$ is transformed in the $\mathrm{Fe}_{2} \mathrm{O}_{3}$ product in the agglomeration process.

The XPS characterizations for comparison of the $\beta$-TCP and Zn-TCP are indicated in Fig. 5 . The $\mathrm{Ca}(2 \mathrm{p})$ characteristic peaks of the $\beta$-TCP and $\mathrm{Zn}$-TCP are almost the same, which is like that of the comparison of the $\beta$-TCP with the Fe-TCP. The peaks from $\mathrm{Zn}(2 \mathrm{p})$ at $1044.51 \mathrm{eV}$ and $1021.42 \mathrm{eV}$ are caused by the $\mathrm{Zn}\left(2 \mathrm{p}_{1 / 2}\right)$ and $\mathrm{Zn}\left(2 \mathrm{p}_{3 / 2}\right)$ orbitals of the $\mathrm{Zn}-\mathrm{O}$ bond as shown in Fig. $5(\mathrm{~b}) .^{23}$ The $\mathrm{O}(1 \mathrm{~s})$ and $\mathrm{P}(2 \mathrm{p})$ energy spectra of the $\beta$-TCP and Zn-TCP have high similarity by comparison of the peaks in Fig. 5(c-f). Like the Fe-TCP, the Zn-TCP contains a small quantity of HA. The energy peaks shift a little because some $\mathrm{Ca}^{2+}$ ions are replaced by the $\mathrm{Zn}^{2+}$ ions in the $\beta$-TCP crystalline lattice.

3.1.3. TG-DSC analysis. The TG-DSC analysis for the products $(2 \%, 5 \%$, and $10 \%$ metal content) was performed, and the results are displayed in Fig. 6. All the tested products have a similar two-step thermolysis curve. Moreover, all the TG curves of the 3 samples show a similar change tendency. Each sample desorbs water at $\sim 100{ }^{\circ} \mathrm{C}$. Decomposition of the possible nitrate presence in the products occurs in the $100-200{ }^{\circ} \mathrm{C}$ range. Decomposition of the main content calcium deficient hydroxyapatite (CDHA) phosphate was observed in the $200-400{ }^{\circ} \mathrm{C}$ range, which transforms into $\beta$-TCP and $\mathrm{H}_{2} \mathrm{O}$. After heating to $400{ }^{\circ} \mathrm{C}$, almost no weight changes of the samples were found. The TGDTA curves of the Zn products are displayed in Fig. 6 with the content of $2 \%, 5 \%$, and $10 \%$ of $\beta$-TCP respectively. Like that of the Fe-TCP samples, the TG curves show almost the same change rule and the tendency for all the three samples with different metal content, which are in high accordance with that of the FeTCP products except for a little shift of the endothermic and exothermic peaks on the temperature scale.
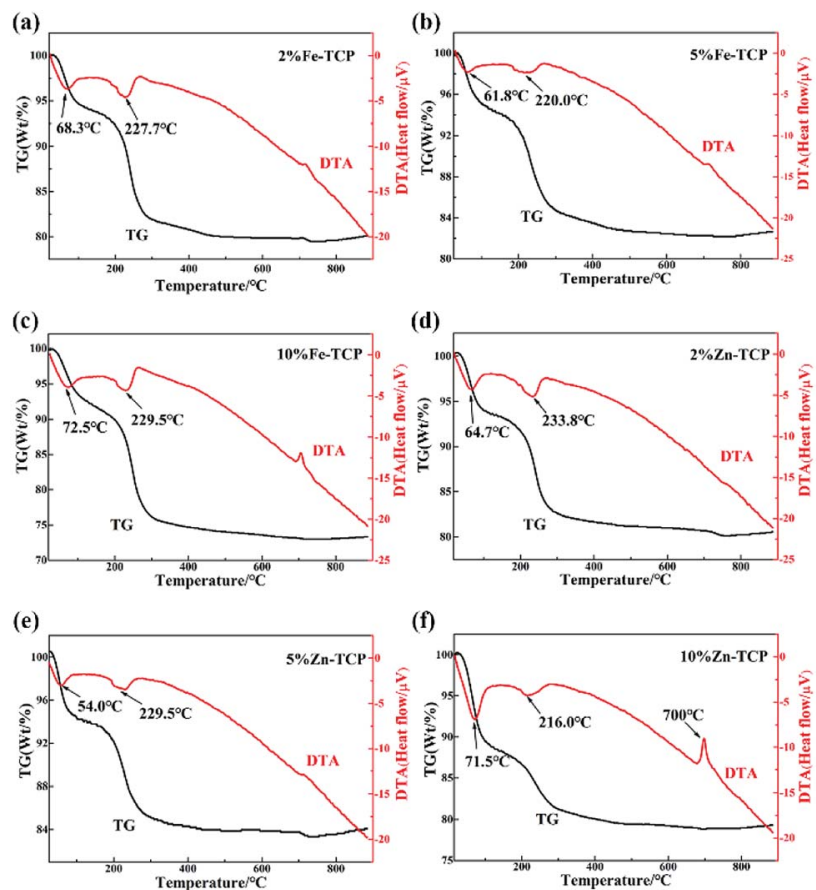

Fig. 6 TG-DTA of Fe-TCP with (a) 2\%, (b) 5\%, and (c) 10\%; and TG-DTA of $\mathrm{Zn}-\mathrm{TCP}$ with (d) $2 \%$, (e) $5 \%$, and (f) $10 \%$ content. 


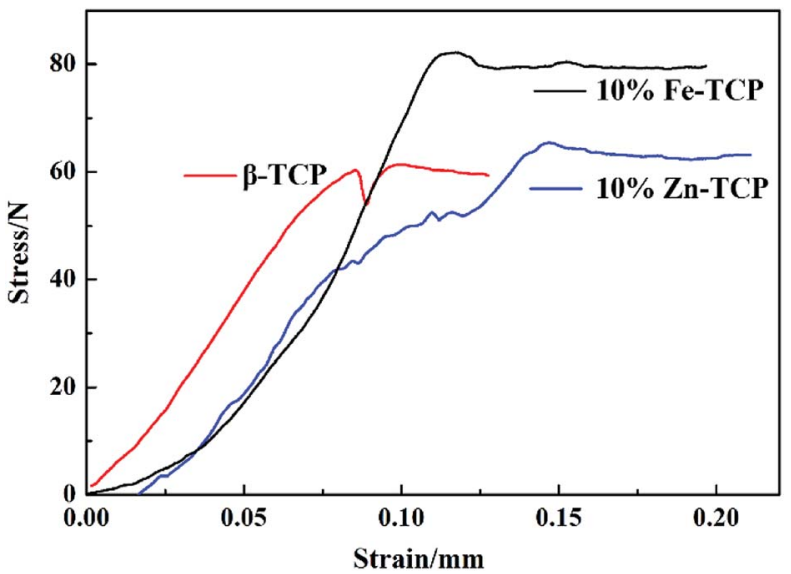

Fig. 7 Stress-strain curves of porous Fe-TCP and Zn-TCP.

Table 1 Mechanical properties of $\beta$-TCP, Fe-TCP, and Zn-TCP

\begin{tabular}{lllll}
\hline Sample & $\begin{array}{l}\text { Maximum } \\
\text { compressive } \\
\text { strength } \\
(\mathrm{MPa})\end{array}$ & $\begin{array}{l}\text { Maximum } \\
\text { load } \\
(\mathrm{N})\end{array}$ & $\begin{array}{l}\text { Maximum } \\
\text { load } \\
\text { deformation } \\
(\mathrm{mm})\end{array}$ & $\begin{array}{l}\text { Modulus of } \\
\text { elasticity } \\
\left(\mathrm{N} \mathrm{mm}^{-2}\right)\end{array}$ \\
\hline$\beta$-TCP & 1.24 & 62.07 & 0.08 & 863.57 \\
Fe-TCP & 1.65 & 82.83 & 0.12 & 770.91 \\
Zn-TCP & 1.32 & 66.09 & 0.15 & 653.47 \\
\hline
\end{tabular}

\subsection{Biological properties}

3.2.1. Mechanical test. The stress-strain test of the Fe/ZnTCP samples was performed, and the results are shown in Fig. 7. The corresponding mechanical parameters of the samples are compared in Table 1 . The modulus elasticity of the $\beta$-TCP is $863.57 \mathrm{~N} \mathrm{~mm}^{-2}$, and the maximum load deformation is $0.08 \mathrm{~mm}$, which corresponds to a maximum compressive strength of 1.24 MPa. The modulus elasticity of the $10 \% \mathrm{Fe}-\mathrm{TCP}$ is $770.91 \mathrm{~N} \mathrm{~mm}^{-2}$, and the maximum load deformation is 0.12 $\mathrm{mm}$, which is equivalent to a maximum compressive strength of 1.65 MPa with a 33\% increase in comparison with the $\beta$-TCP. This may be caused by the replacement of the $\mathrm{Ca}^{2+}$ ions by the $\mathrm{Fe}^{3+}$ ions but without the impact on the crystal structure, which is confirmed by the XRD analysis. The micropore size among the crystal particles is decreased with the increase of $\mathrm{Fe}^{3+}$ doping level that can be observed from the SEM characterization (Fig. S2 and S3, ESI $†$ ). When the metal doping level reaches $10 \%$, the micropores almost disappear and the crystal particles are closely compacted, thus improving the resist compression of the material. The modulus elasticity of the $\mathrm{Zn}$-TCP is $653.47 \mathrm{~N}$ $\mathrm{mm}^{-2}$ and the maximum load deformation is $0.15 \mathrm{~mm}$, which corresponds to a maximum compressive strength of $1.32 \mathrm{MPa}$ with a $6 \%$ increase rate compared with the original $\beta$-TCP. The enhanced effect of the Zn-TCP is less than that of the Fe-TCP.

3.2.2. In vitro release of metal ions. The in vitro releasing test of the products was carried out, and the results are indicated in Fig. 8. It can be seen that the metal ions $\left(\mathrm{Ca}^{2+}\right.$ and $\left.\mathrm{Fe}^{3+}\right)$ concentrations increase with the immersion time. As a typical

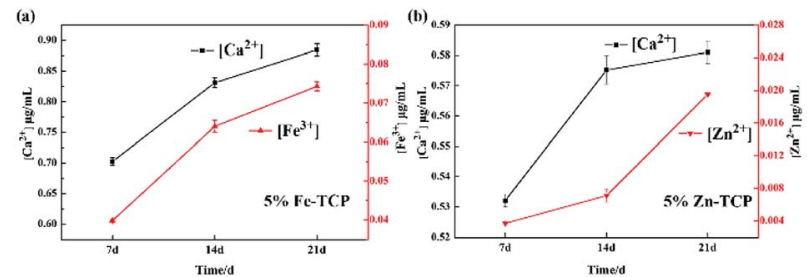

Fig. 8 (a) $\mathrm{Ca}^{2+}$ and $\mathrm{Fe}^{3+}$ releasing curves of 5\% Fe-TCP; (b) $\mathrm{Ca}^{2+}$ and $\mathrm{Zn}^{3+}$ releasing curves of $5 \% \mathrm{Zn}-\mathrm{TCP}$.

example, the releasing rate of the metal ions on the $5 \%$ Fe-TCP sample in the PBS solution is greatly increased versus the immersion time (Fig. 8(a)). The releasing rate of the metal ions reaches to a maximum level when soaking for 7-14 days, which is faster than that for 14-21 days. After the immersion for 21 days, a maximum value of the releasing amount of $\mathrm{Ca}^{2+}$ and $\mathrm{Fe}^{3+}$ ions could be observed at 0.8845 and $0.0743 \mu \mathrm{g} \mathrm{mL}^{-1}$ for each ion, respectively. Thus the goal of the introduction of nutrient elements for bone tissues by the releasing of metal ions could be successfully achieved.

A similar study on the $5 \% \mathrm{Zn}$-TCP was also performed, and the releasing curves are shown in Fig. 8(b). The releasing rate on the $5 \% \mathrm{Zn}$-TCP is almost as the same as that of the $5 \% \mathrm{Fe}-\mathrm{TCP}$. After soaking in the PBS for 21 days, a maximum value of the releasing amount of $\mathrm{Ca}^{2+}$ and $\mathrm{Zn}^{2+}$ ions could achieve as 0.5810 and $0.0195 \mu \mathrm{g} \mathrm{mL} \mathrm{mL}^{-1}$ for each. The slowing releasing rate of metal ions could be used for the supply of nutrient elements for the regeneration of bone tissues. The order of the releasing rate
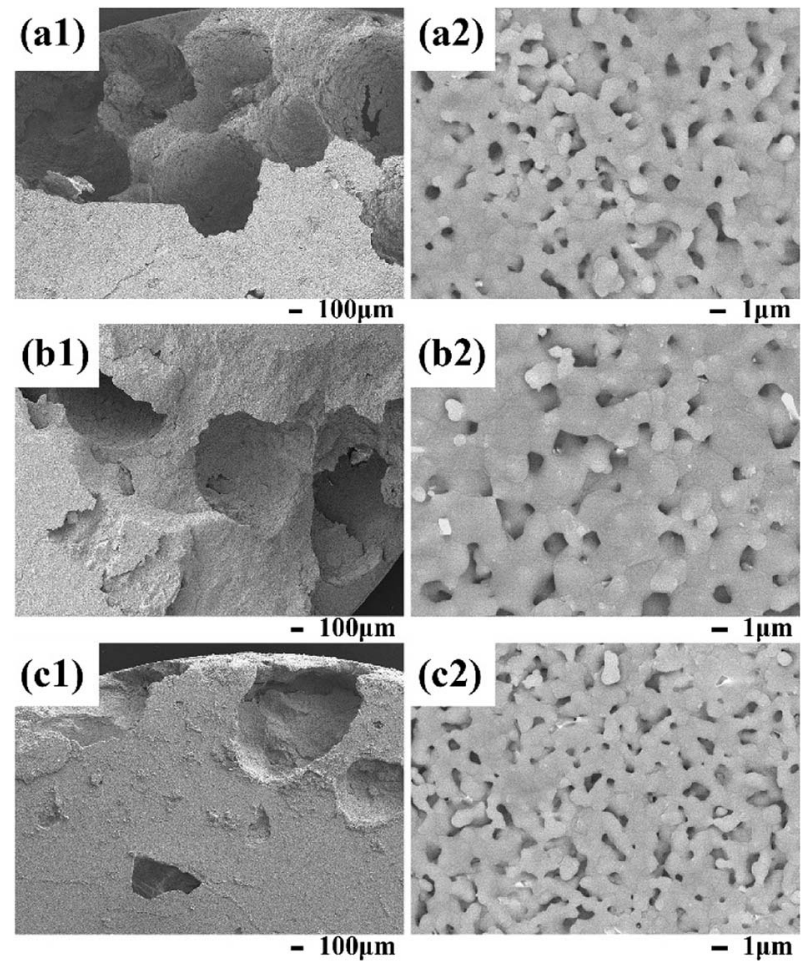

Fig. 9 SEM images of the porous 5\% Fe-TCP soaked in the SBF for (a1) and (a2) 7 d; (b1) and (b2) 14 d; (c1) and (c2) $21 \mathrm{~d}$. 

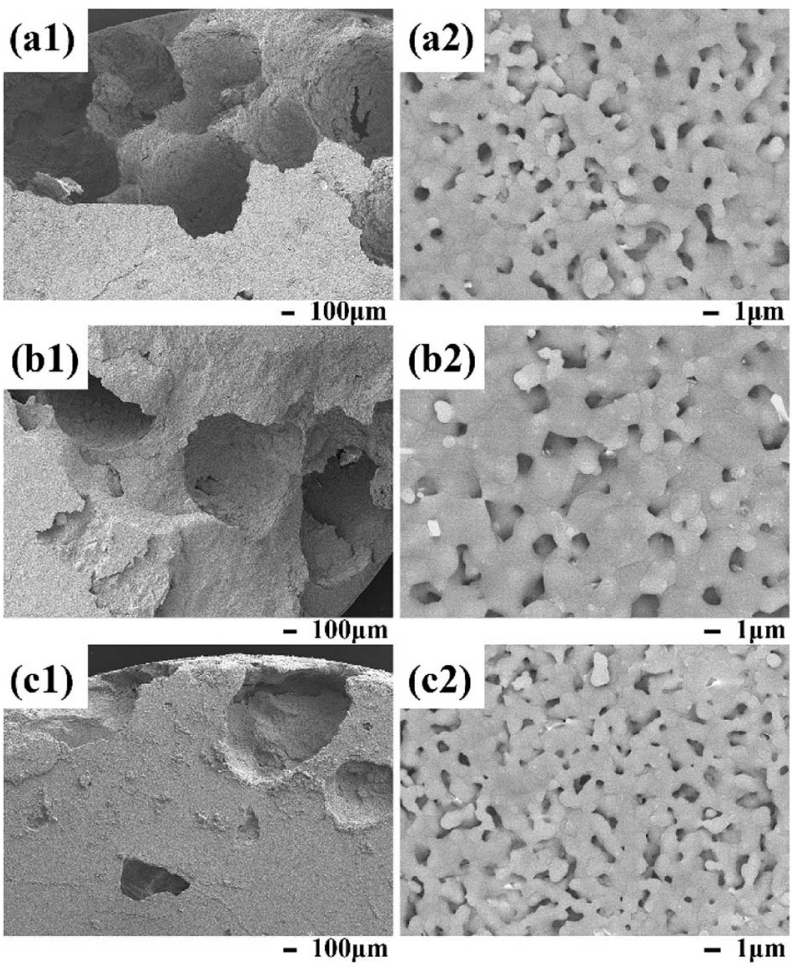

Fig. 10 SEM images of the porous $5 \% \mathrm{Zn}$-TCP soaked in the SBF for (a1) and (a2) $7 \mathrm{~d}$; (b1) and (b2) $14 \mathrm{~d}$; (c1) and (c2) $21 \mathrm{~d}$.

for the metal-TCP samples follows the order: $\left[\mathrm{Ca}^{2+}\right] @$ Fe-TCP $>$ $\left[\mathrm{Fe}^{3+}\right]$ @Fe-TCP $>\left[\mathrm{Ca}^{2+}\right]$ @Zn-TCP $>\left[\mathrm{Fe}^{3+}\right] @ Z n-\mathrm{TCP}$.

3.2.3. In vitro immersion test in SBF. After soaking in $\mathrm{SBF}$ (1.5 times) media, the changes of the 5\% Fe-TCP characterized by SEM are indicated in Fig. 9. The images in Fig. 9(a1-c1) are obtained in low magnification and that in Fig. 9(a2-c2) are the corresponding high-resolution magnifications. The agglomerated clusters of coral-like crystallites with micropores are dispersed on the interior surface. It can be observed that after soaking in the SBF, the boundary of the crystal particles become blurring. The porous size is getting smaller with the increasing soaking time, indicating a deposition layer is formed after the material surface in contact with the simulation solution. The EDS (Energy Dispersive Spectrometer, Fig. S2 and S3, ESI $\dagger$ ) of the material indicates that a layer of phosphorite deposition was formed on the material surface with a $\mathrm{Ca} / \mathrm{P}$ mole ratio of 1.77 (that is 1.85 for Zn-TCP), illustrating the better bioactivity of the Fe/Zn-TCP products. The porosity of the Fe/Zn-TCP is similar as compared in Fig. 9 and 10. The macropore size and their distribution can be ascribed to the same preparation processes.

3.2.4. Weight gain evaluation. The weight gain rate of the $5 \% \mathrm{Fe}-\mathrm{TCP}$ soaking in SBF was investigated and as shown in Fig. 11(a), a noticeable weight gain was found after the soaking treatment for scheduled days. The weight gain is more than $7 \%$ after soaking for 21 days, indicating the induced growth rate of $\mathrm{Ca} / \mathrm{P}$-containing composites onto the material surface in the SBF media. The same test was also performed on the $5 \% \mathrm{Zn}$-TCP (Fig. 11(b)) sample, and the results are similar with that of the
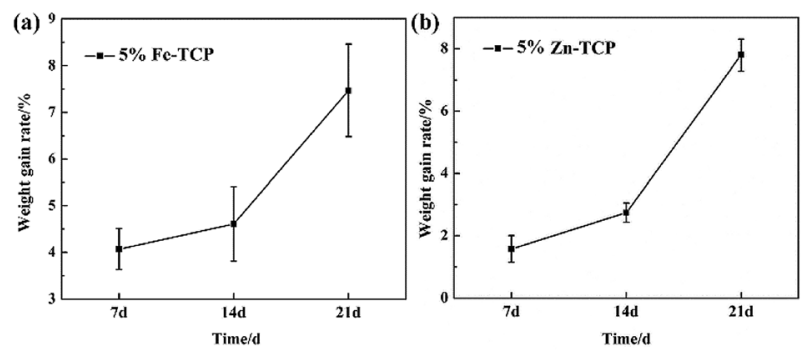

Fig. 11 Weight gain rate of the (a) 5\% Fe-TCP and (b) 5\% Zn-TCP after soaking in the SBF for scheduled days.
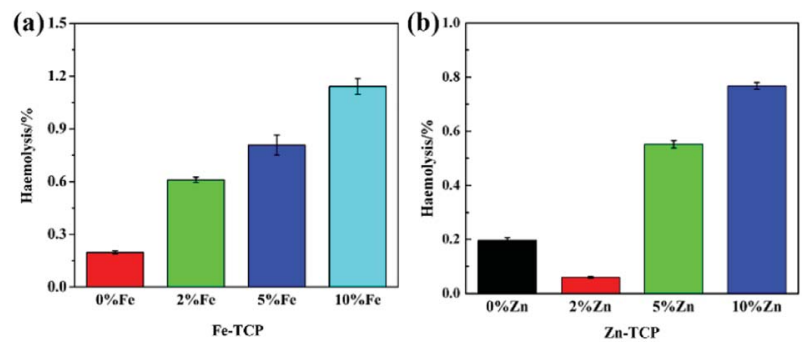

Fig. 12 Hemolysis graph of (a) Fe-TCP and (b) Zn-TCP, * represents $p$ $<0.05$ between groups.

5\% Fe-TCP. The weight gain results illustrate the Fe/Zn-TCP materials have ideal bioactivity.

3.2.5. Hemolysis. Hemolysis of blood may occur when artificial biomaterials are in contact with blood because the hemolysis level is sensitive to the extent of damages to erythrocytes. Bone formation and healing processes can be affected by the interaction between the biomaterials and blood. Hemolysis usually causes the broken of red blood cells (RBC) and the extravasation of the hemoglobin in the tissues. In this study the hemolysis levels on the TCP samples with different doping levels were evaluated. As shown in Fig. 12(a), a hemolytic ratio of less than $0.3 \%$ is observed for the TCP without Fe doping. The hemolytic ratio is increased with the increasing $\mathrm{Fe}^{3+}$ doping

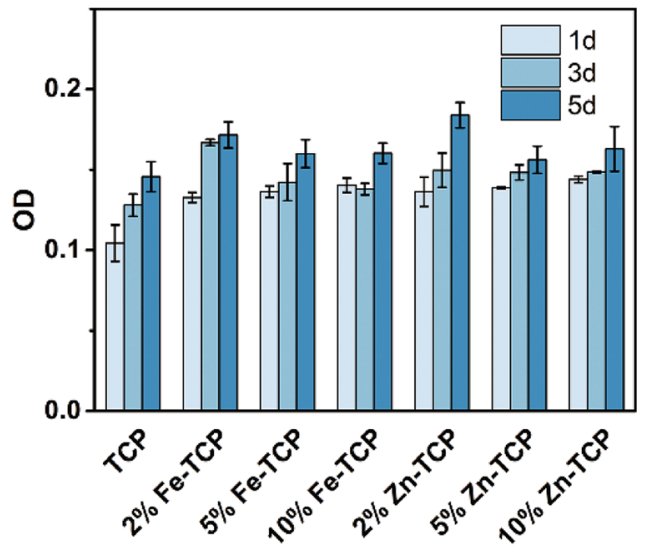

Fig. 13 Optical density measurements of the MG63 cell proliferation on $x \%$ Fe-TCP, $\mathrm{Zn}-\mathrm{TCP}$ after culturing for 1,3 and 5 days. * represents $p<0.05$ between groups. 
Table 2 Cytotoxicity and RGR of MG-63 cells cultured on Fe/Zn-TCP for $5 \mathrm{~d}$

\begin{tabular}{llllllll}
\hline Material & -TCP & $2 \% \mathrm{Fe}$ & $5 \% \mathrm{Fe}$ & $10 \% \mathrm{Fe}$ & $2 \% \mathrm{Zn}$ & $5 \% \mathrm{Zn}$ & $10 \% \mathrm{Zn}$ \\
\hline RGR/\% & 113.6 & 133.8 & 124.7 & 124.9 & 143.4 & 121.8 \\
Reaction grade & 0 & 0 & 0 & 0 & 0 & 0 \\
Cytotoxicity & None & None & None & None & None & None & None \\
\hline
\end{tabular}

level. When the $\mathrm{Fe}^{3+}$ doping level reaches to $10 \%$, the hemolytic ratio is up to $1.2 \%$ that is still of a high hemolysis level. It should be noted that biomaterials have a high hemolysis level when the hemolytic ratio is less than $5 \%$. The results suggested TCP materials with certain $\mathrm{Fe}^{3+}$ doping level will not lead to hemolytic reactions and the Fe-TCP materials have nice hemolysis. Similarly, the hemolysis results of the Zn-TCP are displayed in Fig. 12(b), which show difference from that of Fe-TCP samples. The $2 \% \mathrm{Zn}$-TCP sample has the best hemolysis with a hemolytic ratio of less than $0.2 \%$. The hemolysis assessments demonstrated well hemocompatibility of the Fe/Zn-TCP composites. The $\mathrm{Fe} / \mathrm{Zn}$ dopants at less than certain level will not cause hemolysis reactions.

3.2.6. Cell proliferation (cytotoxicity). Absorbance measurements were used for the evaluation of the cell toxicity. The optical density measurements for the MG-63 cell proliferation of the Fe/Zn-doped TCP after culturing using a CCK-8 assay for scheduled days are shown in Fig. 13. By measuring the optical absorption value of the cells on the Fe/Zn-TCP samples for certain time, the increment level of the MG-63 cells on the material surface can be evaluated. ${ }^{24-26}$ In addition, the cell growth rate (RGR/\%) of the cells is further obtained. Thus the cell toxicity can be determined according to the reaction level standard.

The RGR value was obtained after the cell cultured in the nutrient solution containing Fe/Zn-TCP species for several days and the results are shown in Fig. 13. In vitro activities of the MG63 cells cultivating with the Fe/Zn-TCP biocomposites were tested at 1,3 , and 5 days. Cell proliferation is in close relationship with the amount of the bone formation. Excellent cell proliferation has high possibility to generate a more considerable amount of bone tissues around the implant area. The studied Fe/Zn-TCP composites show ideal time-dependence cell activity according to the RGR data (Table 2). The cells display notable difference among the groups, and the Zn-TCP (10\%) sample possesses the highest cell multiplication among these biomaterials, indicating that the exposure of the Zn-TCP may have a much positive impact on the cytocompatibility. In this case, the bioactivity of the Fe/Zn-TCP materials is improved compared with the pure $\beta$-TCP. The osteogenic activity of the cell on the bio-interfaces, which is correlated with the bonerepair function, plays an important role in bone formation.

\section{Conclusions}

Fe-TCP and Zn-TCP biomaterials were prepared by the codeposition method to enhance the bioactivity of synthetic bone-repair materials. All the pure $\beta$-TCP and the Fe/Zn-TCP samples possess hydroxyapatite as the main component via
$\mathrm{XRD}$ analysis. It was found that part of the $\mathrm{Ca}^{2+}$ ions is replaced by the doping $\mathrm{Fe}^{3+}$ and $\mathrm{Zn}^{2+}$ ions in the TCP crystalline lattice. The presence of the main $\mathrm{Ca} / \mathrm{P}$ component of the TCP was confirmed by TG-DTA measurements. SEM observation indicates a typical porous-containing structure with interconnected micropores for the TCPs. The maximum compression strengths of the Fe-TCP (10\%) and the Zn-TCP (10\%) increase 33\% and $6 \%$ for each compared with the original $\beta$-TCP. The in vitro experiments indicated the Fe/Zn-modified $\beta$-TCP can effectively release $\mathrm{Fe}^{3+}$ and $\mathrm{Zn}^{2+}$ nutrients for a long time. In addition, the bioactivity and dissolution property of the Fe/Zn-TCP in SBF was studied by immersing the samples for scheduled days. The Fe/ Zn-TCP materials demonstrate good biocompatibility with a hemolytic ratio lower than $2 \%$, showing good cell activity. This research will offer a crucial scientific fundamental to propel the metal-TCP biomaterials as novel bone-repair materials with high-performance engineering plasticity for further clinical applications.

\section{Live subject statement}

That all experiments were performed in compliance with relevant laws or guidelines; that all experiments followed institutional guidelines; a statement on the institutional committee(s) that approved the experiments; university and experiments were performed in keeping with national standard "Laboratory Animal-requirements of Environment and Housing Facilities" (GB14925-2001). The care of laboratory animal and the animal experimental operation have conforming to related rules.

\section{Conflicts of interest}

There are no conflicts to declare.

\section{Acknowledgements}

The authors warmly acknowledge the Experimental Technology Project (20170209) of Sichuan University, and the funding from Science \& Technology Department of Sichuan Province (2017JY0270).

\section{Notes and references}

1 L. Xie, H. Y. Yu, Y. Deng, W. Z. Yang, L. Liao and Q. Long, Mater. Sci. Eng., C, 2016, 59, 1007-1015.

2 C. A. Dodd, C. M. Fergusson, L. Freedman, G. R. Houghton and D. Thomas, J. Bone Jt. Surg., Br. Vol., 1988, 70, 431-434.

3 J. G. Seiler, 3rd and J. Johnson, J. South Orthop. Assoc., 2000, 9, 91-97. 
4 S. V. Dorozhkin and M. Epple, Angew. Chem., Int. Ed. Engl,, 2002, 41, 3130-3146.

5 E. Hoonnivathana, P. Pankaew, P. Klumdoung, P. Limsuwan and K. Naemchanthara, Adv. Mater. Res., 2012, 506, 86-89.

6 J. D. Chen, Y. J. Wang, X. F. Chen, L. Ren, C. Lai, W. He and Q. Q. Zhang, Mater. Lett., 2011, 65, 1923-1926.

7 T. Toyama, K. Nakashima and T. Yasue, J. Ceram. Soc. Jpn., 2002, 110, 716-721.

8 A. P. Oliveira, M. Motisuke, C. V. Leal and M. M. Beppu, Key Eng. Mater., 2008, 361-363, 355-358.

9 T. Isobe, S. Nakamura, R. Nemoto, M. Senna and H. Sfihi, J. Phys. Chem. B, 2002, 106, 5169-5176.

10 A. Osaka, Y. Miura, K. Takeuchi, M. Asada and K. Takahashi, J. Mater. Sci.: Mater. Med., 1991, 2, 51-55.

11 D. Algul, A. Gokce, A. Onal, E. Servet, A. I. Dogan Ekici and F. G. Yener, J. Biomater. Sci., Polym. Ed., 2016, 27, 431-440.

12 J. Zhou, T. Fang, Y. Wang and J. Dong, J. Biomed. Mater. Res., 2012, 100A, 2295-2301.

13 X. L. Yin, L. Calderin, M. J. Stott and M. Sayer, Biomaterials, 2002, 23, 4155-4163.

14 N. Matsumoto, K. Yoshida, K. Hashimoto and Y. Toda, Mater. Res. Bull., 2009, 44, 1889-1894.

15 Y. Deng, Y. Y. Yang, Y. Ma, K. X. Fan, W. Z. Yang and G. F. Yin, $R S C A d v$., 2017, 7, 559-573.
16 A. Reindl, R. Borowsky, S. B. Hein, J. Geis-Gerstorfer and P. Imgrund, J. Mater. Sci., 2014, 49, 8234-8243.

17 W. C. Xue, K. Dahlquist, A. Banerjee, A. Bandyopadhyay and S. Bose, J. Mater. Sci.: Mater. Med., 2008, 19, 2669-2677.

18 K. Sariibrahimoglu, J. G. C. Wolke, S. C. G. Leeuwenburgh, Y. B. Li and J. A. Jansen, J. Biomed. Mater. Res., Part B, 2014, 102, 415-422.

19 C. C. Chusuei, D. W. Goodman, M. J. Van Stipdonk, D. R. Justes and E. A. Schweikert, Anal. Chem., 1999, 71, 149-153.

20 T. Yamashita and P. Hayes, Appl. Surf. Sci., 2008, 254, 24412449.

21 Z. Q. Yao, Y. Ivanisenko, T. Diemant, A. Caron, A. Chuvilin, J. Z. Jiang, R. Z. Valiev, M. Qi and H. J. Fecht, Acta Biomater., 2010, 6, 2816-2825.

22 J. K. Heuer and J. F. Stubbins, Corros. Sci., 1999, 41, 12311243.

23 C. Chen, L. Wang, F. M. Li and L. Y. Ling, Mater. Chem. Phys., 2014, 146, 531-537.

24 T. Lu, S. Qian, F. Meng, C. Ning and X. Liu, Colloids Surf., B, 2016, 142, 192-198.

25 S. Wang, Y. Deng, L. Yang, X. Shi, W. Yang and Z. G. Chen, J. Biomater. Sci., Polym. Ed., 2018, 29, 520-542.

26 C. T. Wu, L. G. Xia, P. P. Han, M. C. Xu, B. Fang, J. C. Wang, J. Chang and Y. Xiao, Carbon, 2015, 93, 116-129. 